\title{
Antireflux Transoral Incisionless Fundoplication Using EsophyX: 12-Month Results of a Prospective Multicenter Study
}

\author{
Guy-Bernard Cadière $\cdot$ Michel Buset $\cdot$ Vinciane Muls $\cdot$ Amin Rajan • \\ Thomas Rösch · Alexander J. Eckardt · Joseph Weerts · Boris Bastens • \\ Guido Costamagna - Michele Marchese $\cdot$ Hubert Louis · Fazia Mana • \\ Filip Sermon · Anna K. Gawlicka · Michael A. Daniel · Jacques Devière
}

Published online: 30 April 2008

(C) The Author(s) 2008

\begin{abstract}
Background A novel transoral incisionless fundoplication (TIF) procedure using the EsophyX system with SerosaFuse fasteners was designed to reconstruct a full-thickness valve at the gastroesophageal junction through tailored delivery of multiple fasteners during a single-device insertion. The safety and efficacy of TIF for treating gastroesophageal reflux disease (GERD) were evaluated in a prospective multicenter trial.

Methods Patients $(n=86)$ with chronic GERD treated with proton pump inhibitors (PPIs) were enrolled. Exclusion criteria included an irreducible hiatal hernia $>2 \mathrm{~cm}$. Results The TIF procedure $(n=84)$ reduced all hiatal hernias $(n=49)$ and constructed valves measuring $4 \mathrm{~cm}$ $(2-6 \mathrm{~cm})$ and $230^{\circ}\left(160^{\circ}-300^{\circ}\right)$. Serious adverse events consisted of two esophageal perforations upon device insertion and one case of postoperative intraluminal
\end{abstract}

G.-B. Cadière $(\bowtie)$

Department of Digestive Surgery, Centre Hospitalier

Universitaire St. Pierre, 322 rue Haute, Brussels 1000, Belgium

e-mail: Guy-Bernard_CADIERE@stpierre-bru.be

M. Buset · V. Muls

Department of Gastroenterology, Centre Hospitalier

Universitaire St. Pierre, 322 rue Haute, Brussels 1000, Belgium

A. Rajan

Clinique du Parc Léopold, Centre Hospitalier Régional d'Edith

Cavell (CHIREC), Brussels, Belgium

T. Rösch · A. J. Eckardt

Department of Hepatology and Gastroenterology, Charite

Universitatsmedizin Berlin, Campus Virchow, Berlin, Germany

J. Weerts

Department of Surgery, Centre Hospitalier St. Joseph, Liège, Belgium bleeding. Other adverse events were mild and transient. At 12 months, aggregate $(n=79)$ and stratified Hill grade I tight $(n=21)$ results showed $73 \%$ and $86 \%$ of patients with $\geq 50 \%$ improvement in GERD health-related quality of life (HRQL) scores, $85 \%$ discontinuation of daily PPI use, and $81 \%$ complete cessation of PPIs; $37 \%$ and $48 \%$ normalization of esophageal acid exposure; $60 \%$ and $89 \%$ hiatal hernia reduction; and $62 \%$ and $80 \%$ esophagitis reduction, respectively. More than $50 \%$ of patients with Hill grade I tight valves had a normalized cardia circumference. Resting pressure of the lower esophageal sphincter (LES) was improved significantly $(p<0.001)$, by $53 \%$. EsophyX-TIF cured GERD in 56\% of patients based on their symptom reduction and PPI discontinuation.

Conclusion The 12-month results showed that EsophyXTIF was safe and effective in improving quality of life and for reducing symptoms, PPI use, hiatal hernia, and

\author{
B. Bastens \\ Department of Gastroenterology, Centre Hospitalier St. Joseph, \\ Liège, Belgium \\ G. Costamagna $\cdot$ M. Marchese \\ Digestive Endoscopy Unit, Catholic University of Rome, Rome, \\ Italy \\ H. Louis · J. Devière \\ Department of Gastroenterology and Hepatopancreatology, \\ Université Libre de Bruxelles, Erasme Hospital, Brussels, \\ Belgium \\ F. Mana $\cdot$ F. Sermon \\ Academic Hospital, Vrije Universiteit Brussel (AZ-VUB), \\ Brussels, Belgium \\ A. K. Gawlicka · M. A. Daniel \\ EndoGastric Solutions, Inc., Redmond, WA, USA
}


esophagitis, as well as increasing the LES resting pressure and normalizing esophageal $\mathrm{pH}$ and cardia circumference in chronic GERD patients.

\section{Introduction}

The need for a long-term treatment of gastroesophageal reflux disease (GERD) has become increasingly apparent during the past decade and a half as a result of the growing prevalence and incidence of this chronic disease [1-6]. The likelihood of developing GERD increases with the severity of anatomic change and dysfunction of the gastroesophageal (GE) junction, which represents the primary defense against reflux of gastric content into the esophagus [7-12]. Restoration of the antireflux competence of the GE junction at the anatomic and physiologic levels is critical for effective long-term treatment of GERD [2].

Antireflux surgery has been shown to be more effective in terms of patient satisfaction, clinical outcome, and health care cost reduction than pharmacologic antisecretory therapies in the long-term management of chronic GERD [13-16]. However, side effects of the antireflux fundoplication procedures frequently compromise otherwise excellent postsurgical results $[15,17]$. Persistent dysphagia, inability to belch and vomit, and increased bloating and flatulence are common side effects that may persist for more than 6 months following surgery and prove to be difficult to treat $[13,18-21]$. To minimize the risk of chronic complications, a variety of factors must be taken into account, including the technical aspects of the operation $[20,22]$. "Tailoring" the valve seems to restore the physiology of the GE junction more adequately, allowing air to be vented from the stomach without jeopardizing the efficacy of the antireflux barrier [12, 23].

A novel transoral incisionless device was developed in an attempt to mimics antireflux surgery through constructing a valve at the GE junction, restoring the angle of His, and reducing a small hiatal hernia with fewer side effects. The EsophyX system with SerosaFuse fasteners (EndoGastric Solutions, Redmond, WA, USA) was designed to reconstruct a valve through tailored delivery of multiple fasteners during a single-device insertion [24]. The EsophyX device and the corresponding transoral incisionless fundoplication (TIF) procedure were developed based on the current knowledge and understanding of the anatomic and physiologic functions of the GE junction that was derived from extensive research with open and laparoscopic antireflux surgery [25-28]. The safety and efficacy of the EsophyX-TIF procedure were initially demonstrated by 12-month results from a feasibility study with 19 patients [29]. This article presents results at 6 and
12 months from a prospective multicenter trial with 86 patients that was intended to further evaluate the safety and efficacy of the TIF procedure using the EsophyX system with SerosaFuse fasteners.

\section{Patients and methods}

The study, designed as a prospective multicenter trial, was conducted internationally at seven clinical centers under a common protocol approved by each center's ethics committee. Informed consent was obtained before enrolling patients in the study.

\section{Patient selection}

The study population consisted of patients 18 to 80 years of age with chronic GERD symptoms ( $>6$ months) responsive to proton pump inhibition (PPI) therapy, as judged by GERD health-related quality of life (HRQL) scores of $\leq 12$ while on PPI therapy, whose symptoms recurred upon discontinuation of PPI therapy for 14 days (GERD-HRQL score $\geq 20$ or a difference of $\geq 10$ between the scores on and off PPIs). Pathologic esophageal acid exposure was confirmed by 48-hour pH-metry using the wireless Bravo pH system (Medtronic, Shoreview, MN, USA) [30]. To be included, patients were also required to have a deteriorated GE junction with Hill grade II, III, or IV [26]. Briefly, the Hill grades were defined as follows.

- Grade I valves: presence of a prominent tissue fold surrounding the endoscopic shaft

- Grade II valves: presence of a moderately prominent tissue fold; rarely opens with respiration and closes promptly

- Grade III valves: a barely present fold; fails to close around the endoscope

- Grade IV valves: lack of a muscular fold; lumen of esophagus stays open all the time, allowing the squamous epithelium to be viewed from below

The exclusion criteria were severe reflux esophagitis grade $\mathrm{D}$ in the Los Angeles classification [31]; body mass index (BMI) $\geq 35 \mathrm{~kg} \mathrm{~m}^{-2}$; other esophageal diseases, including biopsy-proven Barrett's esophagus, esophageal motility disorders, esophageal stricture, esophageal ulcer, delayed gastric emptying, irreducible hiatal hernia of $>2 \mathrm{~cm}$; or previously failed antireflux surgery.

During the initial screening phase, patients were evaluated for their medical history including GERD medication usage, and they completed the GERD-HRQL questionnaire while on PPI therapy. The use of PPIs was then discontinued for 14 days, and other GERD medications, such as histamine receptor antagonists (H2RA) or antacids, was 
discontinued for 7 and 2 days, respectively. While off all GERD medications, the GERD-HRQL questionnaire was readministered, and esophageal $\mathrm{pH}$ was assessed over a 48-hour period.

This evaluation was repeated at 3, 6, and 12 months after the procedure. The assessment at the time of screening and at 6 and 12 months also included upper gastrointestinal (GI) endoscopy and optional biopsy. Manometry and barium swallow radiography were performed at screening and at 6 months but were optional at 12 months.

\section{Procedure details}

The TIF procedure using the EsophyX device was designed to create full-thickness serosa-to-serosa plications and construct valves 3 to $5 \mathrm{~cm}$ in length and $200^{\circ}$ to $300^{\circ}$ in circumference [24]. The procedures were performed following a standard TIF1.0 protocol under general anesthesia with either nasal or transoral intubation by a team of two physicians (surgeons and/or gastroenterologists) [24, 29]. The first physician controls the implantation of fasteners using the EsophyX device, and the second operates the endoscope and ensures continuous direct visualization. The device is inserted transorally into the esophagus with the patient in the left lateral position. The hiatal hernia, if present, is reduced by returning the squamocolumnar junction to its natural position below the diaphragm using a built-in vacuum invaginator. During a single insertion, a valve similar to that created through antireflux surgery is reconstructed by retraction of full-thickness plications and tailored placement of multiple fasteners circumferentially around the GE junction starting on the greater curve side of the valve [29].

Patients were instructed to consume a liquid diet during the first 2 weeks and a soft diet during the following 4 weeks. PPIs were discontinued 7 days after the procedure. In the event of symptom recurrence requiring medication, a "step-down" protocol was employed; and patients were returned to their preprocedure dose of PPIs and then weaned from them if possible. There was no TIF retreatment allowed in the present study.

\section{Safety assessment}

The incidences of anticipated and unanticipated serious and nonserious adverse events were carefully recorded. Serious adverse events were defined as complications necessitating hospitalization and medical or surgical intervention. Adverse events and symptoms were recorded and categorized using the Medical Dictionary for Regulatory Activities (MedDRA) classification system developed by the International Conference on Harmonisation (ICH) (http://www. meddramsso.com).

\section{Effectiveness assessment}

The primary effectiveness endpoint was patient quality of life assessed by the validated 10-question GERD-HRQL questionnaire evaluating heartburn-related symptoms and patient satisfaction using a 0 to 5 Visual Analogue Scale [32]. The total GERD-HRQL scores were calculated by summing the responses to nine questions [33]; possible scores ranged between 0 (no symptoms) and 45 (worst symptoms). $A \geq 50 \%$ improvement in the total GERDHRQL scores compared to the baseline off PPIs was considered clinically significant $[34,35]$. The heartburn score was calculated by summing the responses to the first six questions. Absent or rare heartburn (scores of $\leq 2$ to each of the six questions, or a total score of $\leq 12$ ) was indicative of heartburn elimination. Patient satisfaction with their current health condition was evaluated based on question 10 as either "satisfied," "neutral," or "dissatisfied" [32]. Regurgitation was assessed as present or absent by a separate direct question.

Secondary effectiveness endpoints were PPI usage, esophageal acid exposure, hiatal hernia size, reflux esophagitis grade, valve Hill grade, and lower esophageal sphincter (LES) resting pressure. These endpoints allowed thorough, complete evaluation of the competence of the antireflux barrier.

The use of PPIs and other GERD medications, such as H2RA and antacids, was recorded. "Daily" usage of PPIs corresponded to a double dose, full dose, or half dose taken daily for more than $50 \%$ of the total number of days during the follow-up period. "Occasional" or "on-demand" usage was defined as less than a half dose or any daily dose of PPIs taken for less than $50 \%$ of the total number of days during the follow-up period. The designation "none" was used when not a single dose of PPIs was taken during the specified period. Reduction of usage from daily to none or occasional was considered clinically significant.

Esophageal acid exposure corresponded to the percentage of total monitoring time at $\mathrm{pH}<4$; it was normal if it was $\leq 5.3[36,37]$ or significantly improved if it was reduced by $\geq 30 \%$ compared to that pre-TIF, a rate sufficient to eliminate symptoms [38]. During the 48-hour assessment, patients were encouraged to engage in their usual activities [36, 39]. Periods of poor signal reception and capsule displacement to the stomach or intestine were excluded from calculations upon review and recommendation of a validation panel.

Upper GI endoscopy was performed to assess the presence and size of a hiatal hernia. A reduction in hiatal hernia size of at least $50 \%$ compared to that pre-TIF was considered clinically significant. The endoscopy examination also assessed reflux esophagitis following the Los Angeles classification [31] and the geometrical aspects of the TIF 
valves by measuring their Jobe length, defined as the length (in centimeters) from the apex of the fundus to the valve lip [40] and circumference, defined as the distance in degrees between the two most distant fasteners. The valve geometry was evaluated based on the adherence to the endoscope as tight, moderate, or loose and the Hill grade [26], as described above. A one-grade reduction in esophagitis or Hill grade at 12 months compared to that pre-TIF was considered clinically significant.

Cardia circumference was evaluated retrospectively using cardia circumference measurement software and static retroflexed images [41]. A total of 41 patients with clear retroflexed views of the cardia before and 12 months after TIF and the known caliber of the gastroscope were considered eligible for cardia circumference measurements. A total of 15 measurements (three images measured five times each) were taken for each patient and follow-up period after the validated protocol [41] and were used to calculate the mean cardia circumference. A mean cardia circumference of $<34.3 \mathrm{~mm}$ was considered normal [41].

Esophageal manometry was performed in the usual fashion using a stationary pull-through technique [42]. A LES resting pressure of 10 to $40 \mathrm{mmHg}$ was considered normal [43]. Values post-TIF represented the latest follow-up measure.

Effectiveness endpoints were evaluated after discontinuation of PPIs for at least 14 days before TIF and postoperative follow-up visits at 3, 6, and 12 months. Patients served as their own controls, and the outcome values at each follow-up were compared with those before TIF.

A global assessment of all outcome measures was performed for each patient to determine the long-term effectiveness of the EsophyX-TIF procedure in curing GERD. Patients were considered "completely cured" if they had no more heartburn or regurgitation, normal or significantly reduced esophageal acid exposure, eliminated esophagitis, and reduced hiatal hernia. Patients were considered "cured" from GERD if they demonstrated clinically significant alleviation of their symptoms $(\geq 50$ reduction) and discontinued all PPI therapy. Patients were considered "improved" if they required only occasional PPI therapy and had reduced heartburn. Patients with "ongoing GERD" showed no alleviation of their symptoms and required daily PPIs.

A web-based data entry system (Simplified Clinical Data Systems, Milford, NH, USA) with case report forms was employed for real-time data capture at each site. All data were verified against source documents through regular onsite monitoring.

Statistical analysis

Data were analyzed by an independent statistician using SAS statistical software version 8.0 (SAS Institute, Cary,
NC, USA). Continuous variables, summarized by medians and ranges, were considered to represent the population main trends because of the generally skewed data distribution (as indicated by asymmetrical ranges around the medians). Categorical variables were summarized as counts and percentages. The $p$ values for changes at 6 or 12 months compared to pre-TIF were calculated using Wilcoxon's signed rank, sign, McNemar's test, or the Mann-Whitney test. Values of $p<0.05$ were considered significant.

The results at 12 months were stratified into three categories depending on the Hill grade and TIF valve adherence: Hill grade I, tight; Hill grade II, moderate; Hill grade III/IV, loose. Patients with valves that did not fit into the listed categories were excluded from the stratification analysis. Differences among Hill grade groups and followup visits were tested for significance using Spearman's rank correlation or the Kruskal-Wallis test of the equality of medians.

Percentage reduction in esophagitis grade was also calculated without the patients taking daily or occasional PPIs at 12 months to avoid a type 1 error, as the usage of medication represented a confounding variable to the effect of TIF on esophagitis improvement.

Predictors of clinical effectiveness at 12 months were evaluated through nonparametric Spearman's rank correlation coefficient between anatomic and pathophysiologic variables with continuous and ordinal values. Spearman's coefficient $(\rho)$ ranged from -1 to +1 , with negative values indicating that one variable tended to increase as the other decreased and positive values indicating a positive increase of two variables.

\section{Results}

\section{Patient characteristics}

A total of 86 patients were enrolled between April and December 2006 from seven clinical centers in Belgium (five), Germany (one), and Italy (one), with 4 to 27 patients per center. Three patients (3\%) had inclusion/exclusion violations for which they were granted exemptions. Among those patients, one had a pathological 10-question GERDHRQL score on PPIs of 14 but a borderline score off PPIs of 20 and therefore a difference between scores of only 6; and two patients had a BMI of 36. In addition, later validation of the $\mathrm{pH}$ reports identified one patient with a long recording period in the stomach resulting from premature dislodgement of the Bravo capsule on the second day. The exclusion of this gastric period resulted in changing the values of esophageal acid exposure to normal on the worst day (3\% time $\mathrm{pH}<4$ and 13.1 DeMeester score). This 
patient was subsequently excluded from analysis of pH-metry data.

The enrolled 86 patients were 19 to 73 years old (median 44 years, mean \pm SD $44.0 \pm 12.5$ years) (Table 1 ). Overall, the patients had suffered from GERD for a median 6 years (1-33 years) and were on continuous daily PPI medication for 4 years (1-14 years). The median GERDHRQL and heartburn scores pre-TIF increased (worsened) after discontinuation of PPIs from 9 (0-22) to 24 (11-38) and from 7 (0-19) to 21 (10-30), respectively. Before TIF, $100 \%$ of patients were taking either full-dose or half-dose PPIs on a daily basis (Fig. 1). While taking PPIs, 31 (37\%) patients were satisfied, $25(30 \%)$ neutral, and $27(33 \%)$ dissatisfied with their health condition compared to $5(6 \%)$ who were satisfied, 4 (5\%) neutral, and 74 (89\%) dissatisfied after discontinuation of PPIs. Esophagitis was present in $81 \%$ of patients, and $58 \%$ had a hiatal hernia with a median size of $1 \mathrm{~cm}(1-3 \mathrm{~cm})$ (Table 1$)$. Hiatal hernias of $3 \mathrm{~cm}$ in four patients were successfully reduced perioperatively. Biopsy revealed gastritis in $47 \%$ of patients and gastric polyps in $9 \%$. Most of the gastroesophageal valves were Hill grade II or III (Fig. 2). The mean of 77 LES resting pressures was $13.1 \mathrm{mmHg}$ (4-30 $\mathrm{mmHg}$ ). Three patients had LES resting pressures below the lower limit of $10 \mathrm{mmHg}$, but ineffective "hypotonic" esophageal motility disorder was ruled out because they had normal esophageal body amplitude pressure and peristalsis.

Table 1 Patient characteristics at screening

\begin{tabular}{ll}
\hline No. patients & 86 \\
Female/male & $29 / 57(34 \% / 66 \%)$ \\
Age (years) & $44(19-73)$ \\
BMI $\left(\mathrm{kg} \mathrm{m}^{-2}\right)$ & $25.2(17.1-36.1)$ \\
Hiatal hernia & $49 / 85(58 \%)$ \\
Esophagitis & $70(81 \%)$ \\
Gastritis & $21 / 45(47 \%)$ \\
GERD history & \\
GERD duration (years) & $6(1-33)$ \\
$>11$ years & $11(13 \%)$ \\
$\quad 6-10$ years & $34(40 \%)$ \\
3-5 years & $27(31 \%)$ \\
6 months to 2 years & $14(16 \%)$ \\
No. Patients on PPIs & $86(100 \%)$ \\
PPI use duration (years) & $4(1-14)$ \\
$>11$ years & $4(5 \%)$ \\
6-10 years & $21(24 \%)$ \\
$3-5$ years & $41(48 \%)$ \\
$<2$ years & $20(23 \%)$ \\
\hline
\end{tabular}

Values represent medians (range) or counts (\%)

BMI: body mass index; GERD: gastrointestinal reflux disease; PPIs: proton pump inhibitor

\section{Screening $(n=86)$}

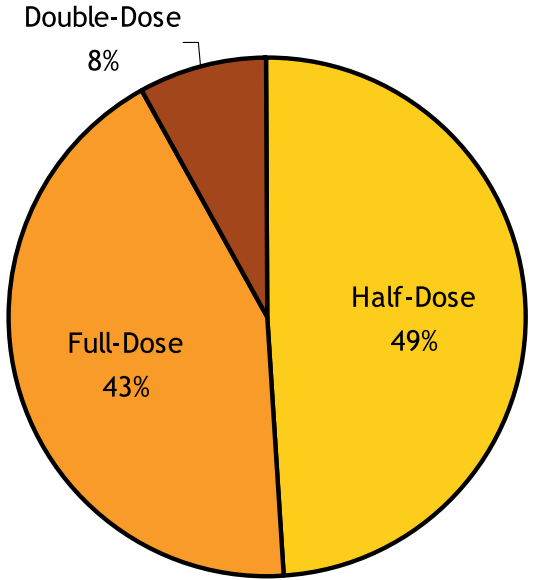

6 Months after TIF $(n=81)$

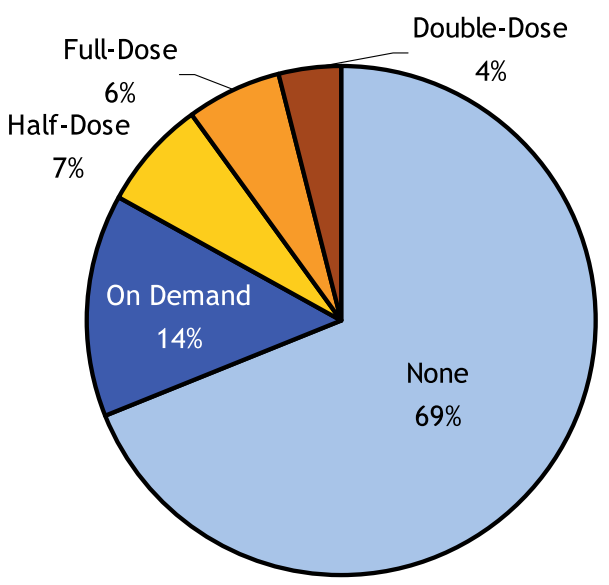

12 Months after TIF $(n=79)$

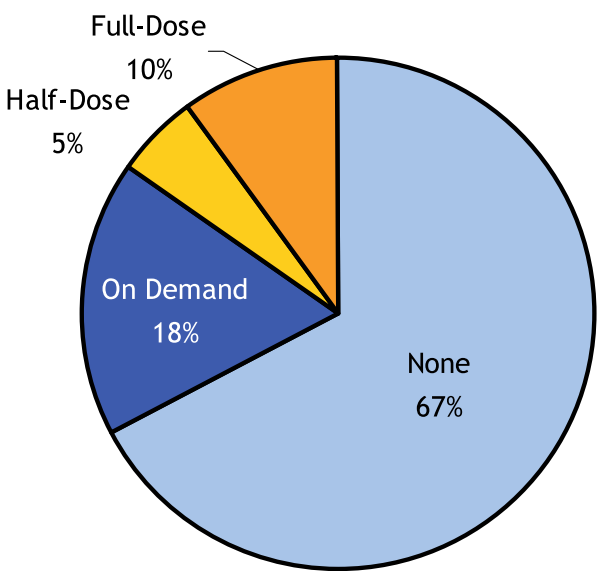

Fig. 1 Usage and dosage of proton pump inhibitors. TIF: transoral incisionless fundoplication

Procedure details

The median procedure time was 77 minutes (28208 minutes). A median of 14 (7-22) SerosaFuse fasteners 


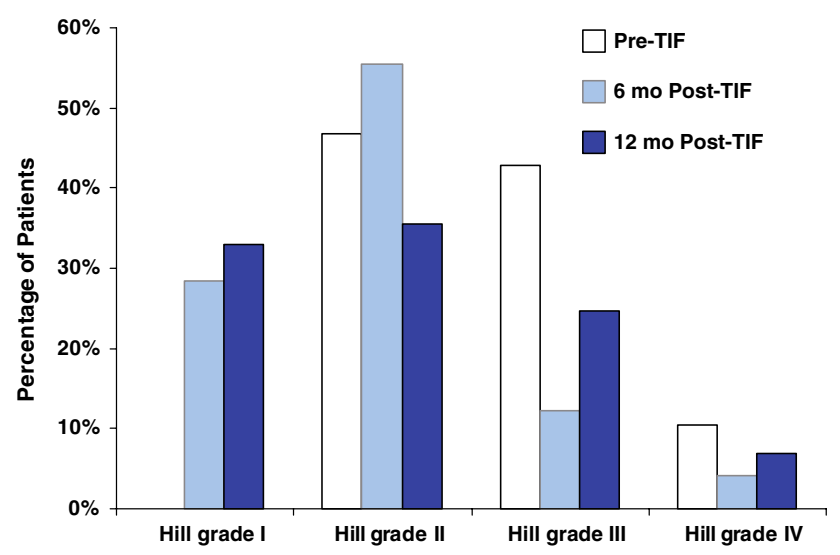

Fig. 2 Hill grade distribution of the valves

were used to construct each TIF valve. In total, 65\% $(55 / 84)$ of procedures were conducted by five teams of two gastroenterologists and the remaining $35 \%$ by two teams of one surgeon and one gastroenterologist. Altogether, $89 \%$ of the procedures were accomplished using a single device. The TIF valves had a median length of $4 \mathrm{~cm}(2-6 \mathrm{~cm})$ and a circumference of $230^{\circ}\left(160^{\circ}-300^{\circ}\right)$. All 49 hiatal hernias were reduced, including the 4 that measured $3.0 \mathrm{~cm}$. Hospitalization stay was 1 day for all but one of the patients; the exception was a patient who experienced intraluminal bleeding and was hospitalized for 5 days (see later).

\section{Safety assessment}

The most common adverse event was musculoskeletal pain in the left shoulder for up to 1 month reported by $16(18 \%)$ patients (Table 2). Other events included abdominal pain $(15 \%)$, sore throat $(8 \%)$, nausea $(8 \%)$, and epigastric pain (7\%). Difficulty swallowing associated with a sore throat

Table 2 Adverse events after the EsophyX-TIF procedure categorized by the MedDRA classification system and grouped by their duration

\begin{tabular}{llll}
\hline Adverse event & $\leq 1$ Week & 1 Week to 1 month $>1$ Month \\
\hline Musculoskeletal pain & $8(9 \%)$ & $8(9 \%)$ & \\
Abdominal pain upper & $8(9 \%)$ & $4(5 \%)$ & $1(1 \%)$ \\
Pharyngolaryngeal pain & $6(7 \%)$ & $1(1 \%)$ & $1(1 \%)$ \\
Nausea & $6(7 \%)$ & & \\
Epigastric pain & $4(5 \%)$ & $2(2 \%)$ & \\
Application site bleeding & $5(6 \%)$ & & \\
Pyrexia & $3(4 \%)$ & & \\
Dysphagia & $3(4 \%)$ & & \\
Diarrhea & $2(2 \%)$ & & \\
Vomiting & $2(2 \%)$ & \\
\hline
\end{tabular}

Values represent number of patients experiencing an adverse event for each of the time periods were reported as dysphagia and lasted up to 1 week after the procedure. All of these nonserious adverse events were mild and resolved spontaneously. Chronic diarrhea, gas bloat, and/or nausea were notably absent.

Three serious adverse events (SAEs) occurred in the study. The first was perforation of the proximal esophagus during advancement of the device without ensuring adequate visualization. The procedure was discontinued, and the injury was immediately repaired with surgical suture following the standard care protocol for managing esophageal perforations [44]. The patient was discharged after 6 days with no sequelae. The second SAE was perforation that occurred during attempted device insertion into the narrow hypopharynx of a patient with Turner's syndrome. The investigators recommended this patient based on adequate endoscopic access, but the esopharynx space proved to be insufficient to allow introduction of the device/endoscope assembly. The perforation was confirmed by computed tomography and surgically repaired after 2.5 hours. The patient was discharged after 21 days. The third SAE consisted of post-TIF intraluminal bleeding and a reported decrease in hemoglobin of $70 \mathrm{~g} \mathrm{~L}^{-1}$. The patient underwent blood transfusion with 4 units of blood, and the bleeding was stopped by applying clips endoscopically and injecting fibrin glue. The patient was discharged after 5 days and remained in the study.

A total of $81(96 \%)$ patients at 6 months and $79(94 \%)$ patients at 12 months (of the 84 treated) completed the follow-up assessment tests and were included in the clinical effectiveness analysis. Seven patients were lost to follow-up (8\%): Two patients with esophageal injury exited the study immediately and later underwent a laparoscopic Nissen fundoplication (LNF); two patients exited the study before the 3-month follow-up (one underwent LNF); one patient failed to return at the 6-month follow-up visit but returned for the 12-month visit; and three patients could not be contacted or were unable to make their 12-month visit. The patients lost to follow-up were included in the safety analysis but excluded from the clinical assessment because of the lack of data.

\section{Clinical effectiveness at 12 months}

The GERD-HRQL scores improved significantly, by $68 \%$, compared to those before TIF and off PPIs (Table 3). A clinically significant improvement in GERD-HRQL scores was achieved by $73 \%$ of patients (Table 3 ). Heartburn scores were significantly reduced in $75 \%$ of patients compared to those off PPIs (Table 3 ). Regurgitation experienced while on and off PPIs was significantly $(p=0.02)$ reduced in $55 \%$ and $59 \%$ of patients, respectively. Complete symptom elimination (GERD-HRQL score $\leq 12$ ) was experienced by $75 \%$ of patients; and $65 \%$ of patients were satisfied, $12 \%$ 
Table 3 GERD health-related quality of life scores and symptoms
HRQL: health-related quality of life; TIF: transoral incisionless fundoplication

${ }^{a}$ Defined by a total score of $\leq 12$ with each of the six questions evaluated as rare (score $\leq 2$ )

\begin{tabular}{|c|c|c|c|}
\hline Parameter & Pre-TIF $(n=82)$ & $\begin{array}{l}6 \text { Months Post-TIF } \\
(n=81)\end{array}$ & $\begin{array}{l}12 \text { Months Post-TIF } \\
(n=79)\end{array}$ \\
\hline \multicolumn{4}{|l|}{ GERD-HRQL score } \\
\hline Median (range) off PPIs & $24(11-38)$ & $5(0-24)$ & $7(0-30)$ \\
\hline Median $\%$ reduction vs. pre-TIF off PPIs & & $80 \%$ & $68 \%$ \\
\hline$p$ & & $<0.0001$ & $<0.0001$ \\
\hline No. reduced by $\geq 50 \%$ & & $62(77 \%)$ & $58(73 \%)$ \\
\hline No. eliminated & & $65(80 \%)$ & $59(75 \%)$ \\
\hline Median (range) on PPIs & $9(0-22)$ & - & - \\
\hline Median $\%$ reduction vs. pre-TIF on PPIs & & $50 \%$ & $22 \%$ \\
\hline$p$ & & $<0.05$ & $>0.05$ \\
\hline \multicolumn{4}{|l|}{ Heartburn score } \\
\hline Median (range) off PPIs & $21(10-30)$ & $4(0-19)$ & $6(0-26)$ \\
\hline Median $\%$ reduction vs. pre-TIF off PPIs & & $79 \%$ & $67 \%$ \\
\hline$p$ & & $<0.0001$ & $<0.0001$ \\
\hline No. reduced by $\geq 50 \%$ & & $62(77 \%)$ & $59(75 \%)$ \\
\hline No. eliminated ${ }^{a}$ & & $70(86 \%)$ & $61(77 \%)$ \\
\hline Median (range) on PPIs & $7(0-19)$ & - & - \\
\hline Median $\%$ reduction vs. pre-TIF on PPIs & & $43 \%$ & $22 \%$ \\
\hline$p$ & & $<0.05$ & $>0.05$ \\
\hline \multicolumn{4}{|l|}{ Regurgitation } \\
\hline No. off PPIs & $60(74 \%)$ & $24(30 \%)$ & $25(32 \%)$ \\
\hline No. eliminated & & $37(62 \%)$ & $34(59 \%)$ \\
\hline
\end{tabular}

neutral, and $20 \%$ dissatisfied with their health condition. Cessation of daily PPIs was reported by $85 \%$ of patients (Table 4). The esophageal acid exposure time was significantly reduced or normalized in $61 \%$ of patients (Table 5). The mean LES resting pressure was increased significantly $(p<0.001)$, by $53 \%$, to $18.2 \mathrm{mmHg}(4-43, n=75)$ (Fig. 3).

Upper GI endoscopy revealed that the TIF valves (Fig. 4) were $2.5 \mathrm{~cm}(1-5 \mathrm{~cm})$ in length and $180^{\circ}\left(0^{\circ}-280^{\circ}\right)$ circumference. Most of the TIF valves were Hill grade I or II (Fig. 2, Table 6). Among the valves with Hill grade III/IV before TIF, 54\% experienced a clinically significant improvement to Hill grade I or II. Gastritis and polyps were absent. Hiatal hernias present in $36 \%$ of patients at 12 months were reduced in size in $60 \%$ of cases (Table 6); the reduction was associated with a reduction of esophagitis in 57\% of those patients. Among patients with esophagitis before TIF, $62 \%$ experienced a significant grade reduction and $40 \%$ total elimination. Among those patients with healed esophagitis, $68 \%$ had grade A before TIF, 24\% had grade B, and $10 \%$ had grade C. Esophagitis elimination in $67 \%$ of cases resulted from eliminating the hiatal hernia and reducing the Hill grade. Comparison of the results among all three follow-up periods ( 3,6 , and 12 months) revealed no significant differences.

Stratification analysis showed that the 21 patients with Hill grade I tight TIF valves at 12 months experienced $75 \%$ improvement in GERD-HRQL scores, $86 \%$ cessation of daily PPIs, $48 \%$ normalization of esophageal acid exposure, and more than $80 \%$ reduction in their hiatal hernias and esophagitis (Table 7). The improvements obtained by these patients were significantly better than those obtained in patients with Hill grade III/IV valves in terms of esophageal acid normalization, hiatal hernia reduction, esophagitis reduction and elimination, and cardia circumference size and normalization. Among-group comparison revealed that the patients in all three groups had the same level of GE junction deterioration at screening (median Hill grade III), a similar median age ( $p=0.3)$, BMI $(p=0.4)$, sex and race ratio $(p=0.3)$, and duration of GERD and PPI usage $(p>0.05)$; they differed significantly $(p<0.05)$ in the occurrence and size of their hiatal hernias and the LES resting pressure: $16.4 \pm 1.4$ for Hill grade I, $13.0 \pm 1.3$ for Hill grade II, and $11.7 \pm 1.1$ for Hill grade III/IV $(p=0.045)$.

Global assessment revealed that $56 \%$ of patients $(n=45)$ were "cured" of their GERD based on the clinically significant reduction of their heartburn and complete cessation off PPIs, which were accompanied with normalization or significant reduction of esophageal acid exposure in $80 \%$ of cases (Fig. 5). Among the cured patients, $24 \%(n=19)$ were "completely cured," as they experienced total elimination of symptoms, esophagitis, and hiatal hernia as well as normalization of esophageal 
Table 4 Use of proton pump inhibitors (PPIs), histamine receptor antagonists (H2RA), and antacids before and after the EsophyX-TIF procedure

\begin{tabular}{lclll}
\hline Medication & No. & Daily & Occasional & None \\
\hline PPIs & & & & \\
$\quad$ Pre-TIF & 86 & $86(100 \%)$ & 0 & 0 \\
6 Months & 81 & $14(17 \%)$ & $11(14 \%)$ & $56(69 \%)$ \\
$\quad$ 12 Months & 79 & $12(15 \%)$ & $13(16 \%)$ & $54(68 \%)$ \\
H2RA & & & & \\
Pre-TIF & 86 & $3(3 \%)$ & $1(1 \%)$ & $82(95 \%)$ \\
6 Months & 81 & 0 & $1(1 \%)$ & $80(99 \%)$ \\
12 Months & 79 & 0 & $5(6 \%)$ & $74(94 \%)$ \\
Antacids & & & $18(21 \%)$ & $68(79 \%)$ \\
Pre-TIF & 86 & 0 & $21(26 \%)$ & $60(74 \%)$ \\
6 Months & 81 & 0 & $23(29 \%)$ & $56(71 \%)$ \\
12 Months & 79 & 0 & & \\
Any GERD medication & & 0 & 0 \\
Pre-TIF & 86 & $86(100 \%)$ & $25(31 \%)$ & $42(52 \%)$ \\
6 Months & 81 & $14(17 \%)$ & $29(37 \%)$ & $38(48 \%)$ \\
12 Months & 79 & $12(15 \%)$ & &
\end{tabular}

Usage was defined as "daily" when $\geq$ half dose was taken for $\geq 50 \%$ of the preceding follow-up period; as "occasional" when $\leq$ half dose taken for $<50 \%$ of the preceding follow-up period; and as "none" when no medication was taken during the specified period

Values represent counts $(\%)$

Table 5 Esophageal $\mathrm{pH}$ monitoring

\begin{tabular}{|c|c|c|c|}
\hline Parameter & $\begin{array}{l}\text { Pre-TIF } \\
(n=82)\end{array}$ & $\begin{array}{l}6 \text { Months } \\
\text { Post-TIF } \\
(n=81)\end{array}$ & $\begin{array}{l}12 \text { Months } \\
\text { Post-TIF } \\
(n=71)^{\mathrm{a}}\end{array}$ \\
\hline \multicolumn{4}{|l|}{ Percentage of time $\mathrm{pH}<4$} \\
\hline Median (range) & $10(3-67)$ & $7(1-29)$ & $7(0-22)$ \\
\hline Median $\%$ reduction & & 31 & 33 \\
\hline$p$ & & $<0.001$ & 0.02 \\
\hline Normalized $^{\mathrm{b}}$ & & $33(41 \%)$ & $26(37 \%)$ \\
\hline $\begin{array}{l}\text { Significantly } \\
\text { reduced }^{\mathrm{c}} \\
\text { or normalized }\end{array}$ & & $46(57 \%)$ & $43(61 \%)$ \\
\hline \multicolumn{4}{|l|}{ DeMeester score } \\
\hline Median (range) & $34(11-222)$ & $24(4-107)$ & $28(1-76)$ \\
\hline Median $\%$ reduction & & 28 & 24 \\
\hline$p$ & & $<0.001$ & $<0.001$ \\
\hline
\end{tabular}

${ }^{a}$ Data were missing for eight patients because of technical problems with Bravo $(n=5)$, contraindications due to other health problems $(n=2)$, or refusal $(n=1)$

b Defined by $\mathrm{pH}<4$ for $\leq 5.3 \%$ of the total monitoring time [36]

${ }^{c}$ Defined by a delta of $\geq 30 \%$ compared to baseline off PPIs

acid exposure. Most of these patients had Hill grade I or II valves. The "improved" group consisted of $22 \%$ of patients who experienced $80 \%$ reduction of their symptoms, were off daily PPIs, and had reduced hiatal hernia or

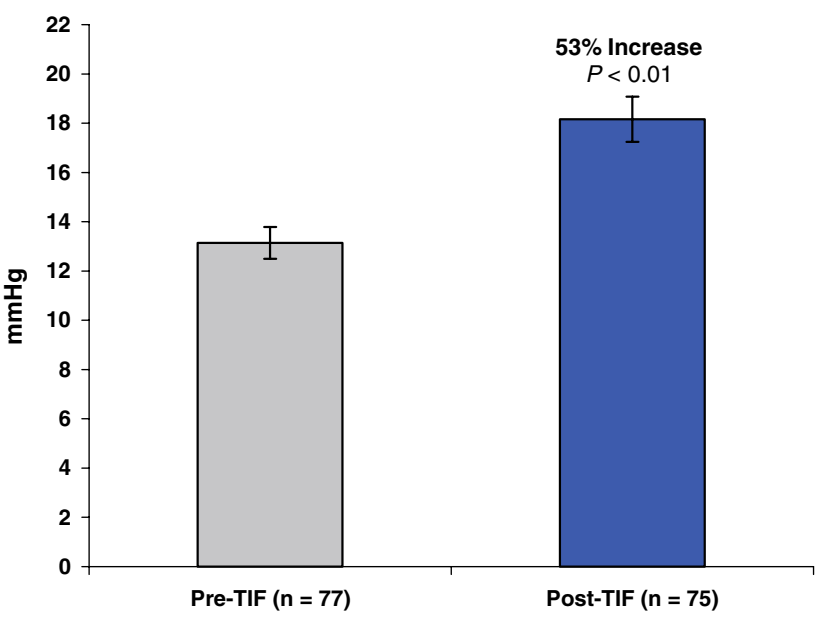

Fig. 3 Resting pressure of lower esophageal sphincter (LES) determined by manometry before and after the EsophyX-TIF procedure

esophagitis. The remaining $22 \%$ of patients had "ongoing" GERD as they continued to experience GERD symptoms and required daily PPI therapy.

Correlation analysis at 12 months revealed a significant relation $(\rho>0.5, p<0.001)$ between the valve's Hill grade and hiatal hernia size, esophagitis grade, LES resting pressure, and cardia circumference (Table 8). Esophageal acid exposure correlated most significantly with hiatal hernia size.

\section{Discussion}

The patient population participating in this study suffered from severe chronic GERD. Most of the patients had had GERD for more than 6 years, experienced frequent and severe heartburn and regurgitations, and used PPIs at a daily dose of 20 to $80 \mathrm{mg}$ for more than 3 years. The high prevalence of hiatal hernia, esophagitis, and gastritis reflected an advanced level of the disease. Gastritis and gastric polyps have been associated with prolonged PPI use [45-47]. Upper GI endoscopy confirmed that deterioration of the GE junction (Hill grade II or III) appeared concomitantly with the presence of high esophageal acid exposure, esophagitis, and/or hiatal hernia. Patients with similar characteristics are typically referred for antireflux surgery $[15,17]$ or treated with increasing doses of PPIs [48, 49].

The two esophageal perforations experienced in this study were associated with device insertion. They underline the caution required during this stage of transoral surgery [50] and the need for careful pretherapeutic patient assessment [23]. In approximately 330 TIF cases that have been performed worldwide to date, these were the only two 
Fig. 4 Endoscopic images of gastroesophageal valves from two patients who had Hill grade IV valves, esophagitis A, and a $2 \mathrm{~cm}$ hiatal hernia before TIF. At 6 and 12 months post-TIF both patients had Hill grade I valves, no hiatal hernia, and no esophagitis
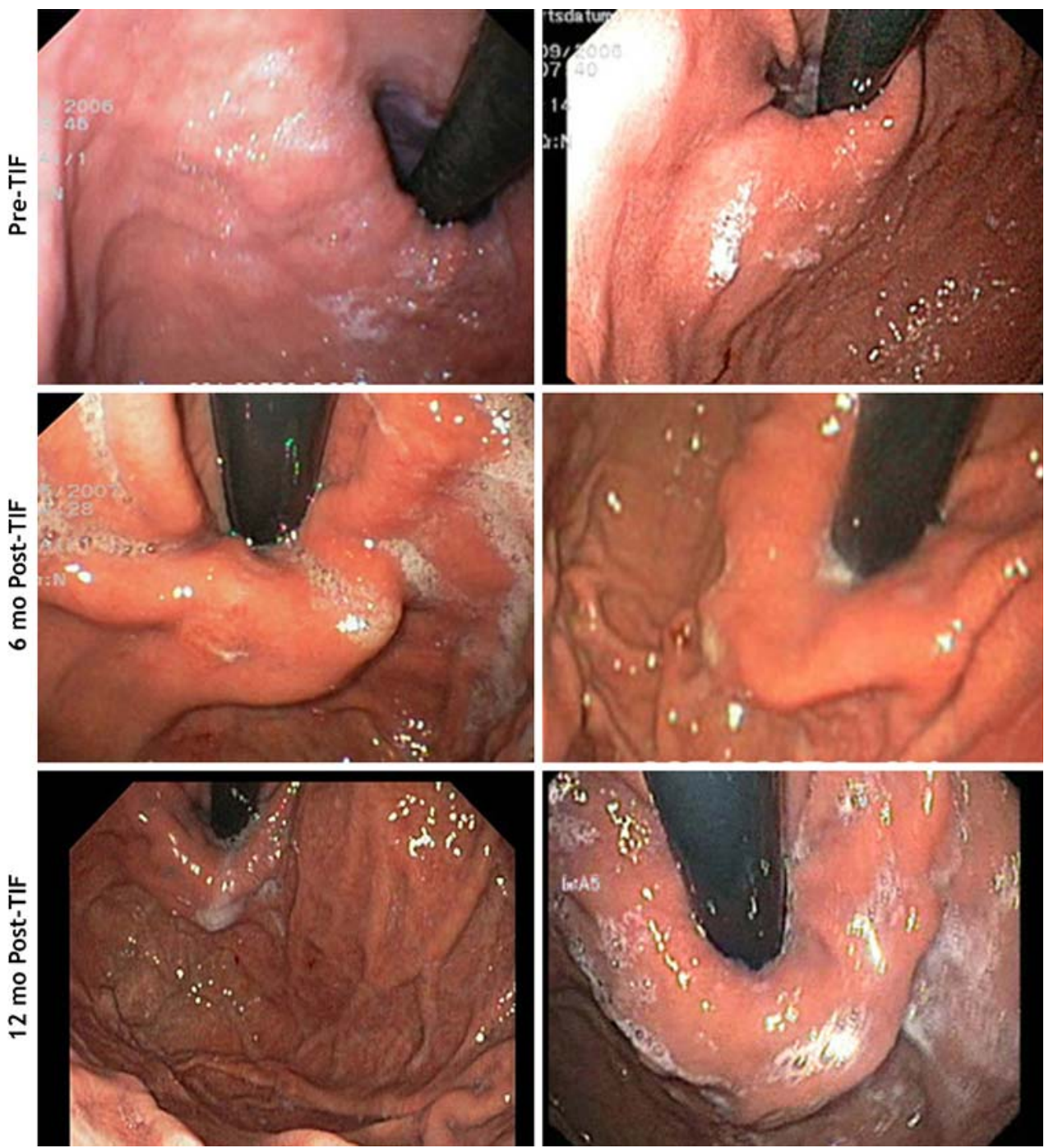

known instances of esophageal injury upon device insertion [51]. They might have been avoided by careful device introduction under continuous endoscopic visualization and by excluding patients with abnormal or unusually narrow esophageal anatomy. Additional refinement in the design of the device may also help reduce this risk. The reported instance of intraluminal bleeding at one fastener site was the only serious complication that resulted directly from the TIF procedure. Tissue compression inherent in the device design and delivery method most likely accounts for the low incidence of intraluminal bleeding.

The side effects reported after the TIF procedure were few, mild, and transient. Shoulder pain, which was reported by $18 \%$ of patients, is typically associated with antireflux laparoscopic surgery and results from indirect or direct irritation of the phrenic nerve and the resulting dermatome response [52]. The abdominal pain reported in $15 \%$ of patients most likely resulted from insufflation during the procedure and was proportional to the extent of insufflation and procedure duration. Epigastric pain experienced by $7 \%$ of patients was most likely associated with transmural serosal fastening. Pharyngolaryngeal pain, reported as sore throat by $8 \%$ of patients, was assumed to be caused by insertion of the $18 \mathrm{~mm}$ device and its repetitive rotations around the longitudinal axis during the procedure. Nausea present in $7 \%$ of patients could result from insufflation, anesthesia, or manipulation of tissue at the GE junction that possibly stressed the vagus nerve. The postoperative dysphagia experienced by $4 \%$ resulted from swelling at the GE junction and resolved within 7 days without intervention. Chronic side effects typically associated with laparoscopic fundoplication (e.g., dysphagia, gas bloat, diarrhea) [19, 20,53 ] were notably absent after TIF. The difference in the incidence of these complications probably resulted from the absence of any surgical dissection and of wrapping the greater gastric curvature around the esophagus, both of 
Table 6 Endoscopic evaluation

\begin{tabular}{|c|c|c|c|}
\hline Parameter & $\begin{array}{l}\text { Pre-TIF } \\
(n=82)\end{array}$ & $\begin{array}{l}6 \text { Months } \\
\text { Post-TIF } \\
(n=81)\end{array}$ & $\begin{array}{l}12 \text { Months } \\
\text { Post-TIF } \\
(n=77)^{\mathrm{a}}\end{array}$ \\
\hline \multicolumn{4}{|l|}{ Hill grade } \\
\hline I & 0 & $22(29 \%)$ & $24(33 \%)$ \\
\hline II & $35(45 \%)$ & $42(55 \%)$ & $26(36 \%)$ \\
\hline III & $34(44 \%)$ & $10(13 \%)$ & $18(25 \%)$ \\
\hline IV & $9(12 \%)$ & $3(4 \%)$ & $5(7 \%)$ \\
\hline \multicolumn{4}{|l|}{ Hiatal hernia } \\
\hline None & $33(41 \%)$ & $58(72 \%)$ & $49(64 \%)$ \\
\hline $1 \mathrm{~cm}$ & $11(14 \%)$ & $7(9 \%)$ & $12(16 \%)$ \\
\hline $2 \mathrm{~cm}$ & $33(41 \%)$ & $14(17 \%)$ & $10(13 \%)$ \\
\hline $3 \mathrm{~cm}$ & $4(5 \%)$ & $2(3 \%)$ & $6(8 \%)$ \\
\hline \multirow[t]{2}{*}{ Reduced } & & $35 / 47(74 \%)$ & $27 / 45(60 \%)$ \\
\hline & & $p<0.001$ & $p<0.001$ \\
\hline Eliminated & & $29 / 47(62 \%)$ & $22 / 45(49 \%)$ \\
\hline \multicolumn{4}{|l|}{ Esophagitis } \\
\hline None & $14(17 \%)$ & $37(46 \%)$ & $35(45 \%)$ \\
\hline Grade A & $31(38 \%)$ & $26(32 \%)$ & $22(29 \%)$ \\
\hline Grade B & $27(33 \%)$ & $14(17 \%)$ & $14(18 \%)$ \\
\hline Grade C & $10(12 \%)$ & $3(4 \%)$ & $5(6 \%)$ \\
\hline Grade D & 0 & $1(1 \%)$ & $1(1 \%)$ \\
\hline \multirow[t]{2}{*}{ Reduced $^{\mathrm{b}}$} & & $42 / 67(63 \%)$ & $39 / 63(62 \%)$ \\
\hline & & $p<0.001$ & $p<0.001$ \\
\hline Eliminated $^{\mathrm{b}}$ & & $26 / 67(39 \%)$ & $25 / 63(40 \%)$ \\
\hline
\end{tabular}

${ }^{a}$ Data are missing for two patients whose examinations were contraindicated because of other health problems

b After excluding patients taking daily PPIs, at 6 and 12 months esophagitis was reduced in $61 \%$ and $58 \%$ of patients and eliminated in $39 \%$ and $37 \%$ of patients, respectively

which contribute to the observed side effects after Nissen fundoplication [17, 20, 54].

The results at 12 months supported the clinical effectiveness of the TIF procedure in treating patients with chronic GERD. The overall median improvement in GERD-HRQL of $68 \%$ reported at 12 months post-TIF resulted in a complete symptom resolution in $75 \%$ of patients. Although quality of life is subjective, patients typically request treatment for their heartburn rather than for their esophagitis or abnormal esophageal acid exposure $[2,3,15]$. Although the reduction in GERD symptoms at 12 months was similar to that obtained while on PPIs, TIF resulted in higher patient satisfaction than with PPI therapy. The elimination of daily PPI dependence in $85 \%$ of patients at 12 months after the EsophyX-TIF procedure was also encouraging.

The TIF procedure was shown to be effective in reducing small hiatal hernias $(\leq 2 \mathrm{~cm})$. EsophyX has been identified as the only transoral device that is capable of reducing small hiatal hernias [50]. It was hypothesized that the durability of the reduction of hiatal hernias through TIF was accomplished by tightening the phrenoesophageal membrane, which is one of the intrinsic components of the antireflux barrier $[55,56]$. The TIF reduction of small hiatal hernias was durable in $60 \%$ of patients and contributed to the significant reduction in esophageal acid exposure and esophagitis in the patients. Several studies have demonstrated similar beneficial changes in anatomy and physiology of the GE junction after eliminating a hiatal hernia, especially in terms of healing esophagitis, normalization of esophageal acid exposure, and increasing the LES resting pressure [9-11].

Restoration of the deteriorated GE junctions to Hill grade I tight valves resulted in elimination of GERD symptoms, total cessation of daily PPI use, and healing of esophagitis in more than $80 \%$ of patients. The level of effectiveness achieved at 12 months by $27 \%$ of patients with Hill grade I tight valves was significantly correlated with reduction of the hiatal hernia, normalization of the cardia circumference, and the increase in LES resting pressure. The demonstrated significant correlation between the quality of anatomic reconstruction and the improvement in clinical and pathophysiologic outcome measures provides compelling evidence to support the ability of the TIF procedure to improve the antireflux competence of the GE junction.

Although the exact underlying mechanism of TIF valves remains under investigation, the total resolution of GERD symptoms and the healing of esophagitis achieved in most of the patients in this study, especially in those with Hill grade I tight valves, are strong evidence indicating that the TIF valves contributed to a better mechanical barrier, thereby preventing GE reflux. Moreover, the durable and effective repair of small hiatal hernias, the significantly increased LES resting pressure, the narrowed cardia, and the re-created acute angle of His support the ability of the TIF procedure to enhance the competence of the antireflux barrier. The fact that preoperative hiatal hernias were smaller and less common among patients with Hill grade I tight valves (44\%) than those with Hill grade II moderate valves $(67 \%)$ and Hill grade III/IV loose valves $(71 \%)$ at 12 months suggested that patients with small $(\leq 2 \mathrm{~cm})$ or no hiatal hernia might be the best initial candidates for this procedure as they experienced the best outcome in terms of esophagitis healing and symptom relief.

The 12-month results demonstrated that the level of clinical and anatomic improvements obtained following the TIF procedure was sustained over time. Technical expertise, the quality of the tailored valve, and careful postprocedure patient management have been identified as key factors for achieving the highest level of anatomic repair of the GE junction through TIF. Similar factors have been identified for successful antireflux surgeries [57-59]. 
Table 7 Clinical effectiveness at 12 months stratified into three groups depending on the anatomic characteristics of TIF valves defined by Hill grade and adherence $^{\mathrm{a}}$
${ }^{a}$ Valves not fitting into either category were excluded from stratification

${ }^{\mathrm{b}}$ Patients taking PPIs were excluded

c Normalized cardia circumference if $<34.3 \mathrm{~mm}$ [41]

* The $p$ values for among-group comparisons reflect the exact global test (Spearman's rank correlation) for the trend of lower Hill grade associated with better outcome

\begin{tabular}{|c|c|c|c|c|}
\hline Parameter & $\begin{array}{l}\text { Hill grade I } \\
\text { tight }(n=21)\end{array}$ & $\begin{array}{l}\text { Hill grade II } \\
\text { moderate }(n=21)\end{array}$ & $\begin{array}{l}\text { Hill grade III/IV } \\
\text { loose }(n=14)\end{array}$ & $p^{*}$ \\
\hline GERD-HRQL scores-improved by $\geq 50 \%$ & $18(86 \%)$ & $17(81 \%)$ & $11(79 \%)$ & 0.330 \\
\hline Heartburn—eliminated & $19(90 \%)$ & $17(81 \%)$ & $10(71 \%)$ & 0.122 \\
\hline PPI use-none & $17(81 \%)$ & $18(86 \%)$ & $7(50 \%)$ & 0.091 \\
\hline Esophageal $\mathrm{pH}$-normalized & $48 \%$ & $25 \%$ & $33 \%$ & 0.014 \\
\hline \multicolumn{5}{|l|}{ Hiatal hernia } \\
\hline None post-TIF & $18(86 \%)$ & $14(67 \%)$ & $5(36 \%)$ & 0.002 \\
\hline None pre-TIF & $12(56 \%)$ & $7(33 \%)$ & $4(29 \%)$ & 0.014 \\
\hline Reduced & $8 / 9(89 \%)$ & $10 / 14(71 \%)$ & $3 / 10(30 \%)$ & 0.250 \\
\hline Eliminated & $7 / 9(78 \%)$ & $7 / 14(50 \%)$ & $3 / 10(30 \%)$ & 0.290 \\
\hline \multicolumn{5}{|l|}{ Esophagitis } \\
\hline None post-TIF & $15(71 \%)$ & $9(43 \%)$ & $5(36 \%)$ & 0.001 \\
\hline None pre-TIF & $3(14 \%)$ & $2(10 \%)$ & $3(21 \%)$ & 0.400 \\
\hline Reduced $^{\mathrm{b}}$ & $12 / 15(80 \%)$ & $14 / 19(74 \%)$ & $4 / 11(36 \%)$ & 0.010 \\
\hline Eliminated $^{\mathrm{b}}$ & $9 / 15(60 \%)$ & $7 / 19(37 \%)$ & $3 / 11(27 \%)$ & 0.002 \\
\hline \multicolumn{5}{|l|}{ Cardia circumference (mm) } \\
\hline Post-TIF & 32.8 & 37.5 & 40.4 & 0.001 \\
\hline Pre-TIF & 43.3 & 46.8 & 41.3 & 0.050 \\
\hline Normalized $^{\mathrm{c}}$ & $9 / 16(56 \%)$ & $4 / 12(33 \%)$ & $1 / 12(8 \%)$ & 0.040 \\
\hline
\end{tabular}

\section{Conclusion}

The 12-month results of this prospective multicenter study showed that the TIF procedure using the EsophyX system with SerosaFuse fasteners was effective in improving

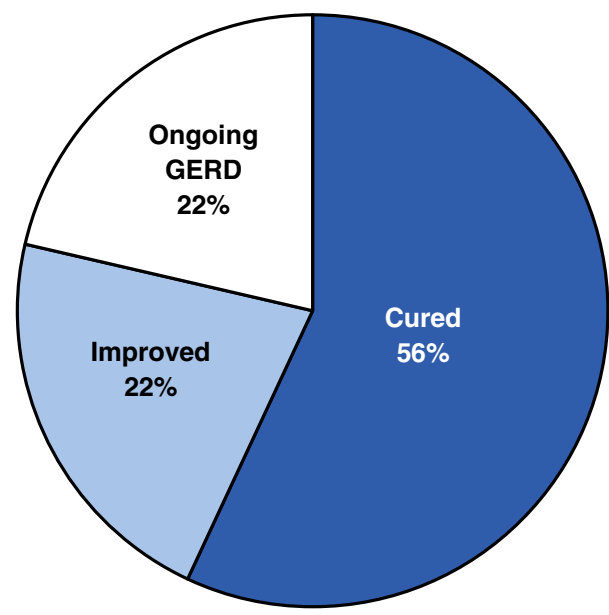

Fig. 5 Study population divided into three groups depending on the degree of cure from gastroesophageal reflux disease (GERD) based on the long-term clinical effectiveness of EsophyX-TIF. Cured: patients demonstrated clinically significant alleviation of their symptoms and discontinued their usage of proton pump inhibitor (PPI) therapy. Improved: patients required only occasional PPI therapy and had reduced heartburn. Ongoing GERD: patients showed no alleviation of their symptoms and required daily usage of PPIs. Among the cured patients, 24\% were "completely cured" of GERD based on total elimination of heartburn and regurgitation, completely healed esophagitis, reduced hiatal hernia, and normalized or significantly reduced esophageal acid exposure quality of life, reducing symptoms, decreasing the need for daily PPIs, reducing esophageal acid exposure, increasing LES resting pressure, and promoting healing of esophagitis in patients with chronic GERD. The obtained improvement in clinical and pathophysiologic outcomes correlated significantly with the quality of the anatomic reconstruction. The side effects related to TIF were few and transient, and the two esophageal perforations resulting from device introduction underline the caution needed during this phase of transoral surgery. The clinical improvements obtained at 12 months after the EsophyX-TIF1.0 procedure in the study population dominated by patients with advanced stages of GERD were encouraging. The tailored fastener placement technique (TIF2.0) is expected to further improve on these results and support the use of EsophyXTIF for the treatment of GERD.

\section{Note}

Based on the results obtained in the present study, the EsophyX/SerosaFuse system was cleared by the U.S. Food and Drug Administration (FDA) in September 2007 and is indicated for use in transoral tissue approximation, full-thickness plication and ligation in the GI tract, for the treatment of symptomatic chronic GERD in patients who require and respond to pharmacologic therapy, and for use in narrowing the GE junction and reducing hiatal hernia of $\leq 2 \mathrm{~cm}$ in patients with symptomatic chronic GERD. 
Table 8 Correlation analysis between symptom intensity, esophageal acid exposure, and anatomic characteristics of gastroesophageal valves 12 months after EsophyX-TIF

\begin{tabular}{|c|c|c|c|c|c|c|}
\hline Parameter & $\begin{array}{l}\text { GERD-HRQL } \\
\text { score }\end{array}$ & $\begin{array}{l}\text { Esophageal } \\
\text { acid exposure }\end{array}$ & Hill grade & $\begin{array}{l}\text { Hiatal hernia } \\
\text { size }\end{array}$ & $\begin{array}{l}\text { Esophagitis } \\
\text { grade }\end{array}$ & $\begin{array}{l}\text { LES resting } \\
\text { pressure }\end{array}$ \\
\hline \multirow[t]{2}{*}{ Esophageal acid exposure } & 0.259 & & & & & \\
\hline & $p=0.061$ & & & & & \\
\hline \multirow[t]{2}{*}{ Hill grade } & 0.275 & 0.434 & & & & \\
\hline & $p=0.040$ & $p=0.048$ & & & & \\
\hline \multirow[t]{2}{*}{ Hiatal hernia size } & 0.341 & 0.754 & 0.754 & & & \\
\hline & $p=0.111$ & $p=0.000$ & $p=0$ & & & \\
\hline \multirow[t]{2}{*}{ Esophagitis grade } & 0.400 & 0.266 & 0.628 & 0.495 & & \\
\hline & $p=0.000$ & $p=0.054$ & $p=0$ & $p=0.016$ & & \\
\hline \multirow[t]{2}{*}{ LES resting pressure } & -0.298 & -0.396 & -0.533 & -0.125 & -0.411 & \\
\hline & $p=0.185$ & $p=0.061$ & $p=0.009$ & $p=0.185$ & $p=0.014$ & \\
\hline \multirow[t]{2}{*}{ Cardia circumference } & 0.362 & 0.287 & 0.803 & 0.704 & 0.530 & -0.280 \\
\hline & $p=0.049$ & $p=0.043$ & $p=0$ & $p=0$ & $p=0$ & $p=0.133$ \\
\hline
\end{tabular}

Values represent Spearman's rank correlation coefficients and the $p$ values

Acknowledgments We thank Rhimou Saidi, Nathalie Van Sante, Ahmed Khalifa, MD, Vanessa Michels, MD, Carolina Gualtieri, Liliane Collignon, and Marleen Stevens for their excellent assistance as study coordinators. The study was sponsored by EndoGastric Solutions, Inc., Redmond, WA, USA.

Financial Disclosure Statement Author Anna Gawlicka-I was a full-time employee at EndoGastric Solutions and was responsible for managing the trial, data analysis and preparation of the manuscript I did not own any stocks at the time of the trial. Author Michael Daniel, Vice President, Regulatory and Clinical Affairs-I certify that I was initially a consultant for, and then a full-time employee of, EndoGastric Solutions, Inc. during the EsophyX-TIF1.0 Phase 2 trial and was responsible for study design and management including supervising co-author Dr. Anna Gawlicka and others involved in data collection and analysis as well as for preparation of the manuscript. Portions of this data were used to obtain U.S. FDA 510(k) clearance for the EsophyX medical device. I own stock in the Company.

Open Access This article is distributed under the terms of the Creative Commons Attribution Noncommercial License which permits any noncommercial use, distribution, and reproduction in any medium, provided the original author(s) and source are credited.

\section{References}

1. El-Serag HB (2007) Time trends of gastroesophageal reflux disease: a systematic review. Clin Gastroenterol Hepatol 5:17-26

2. Lundell L (2004) Surgery of gastroesophageal reflux disease: a competitive or complementary procedure? Dig Dis 22:161-170

3. Metz DC (2004) Managing gastroesophageal reflux disease for the lifetime of the patient: evaluating the long-term options. Am J Med 117( Suppl 5A):49S-55S

4. Moayyedi P, Talley NJ (2006) Gastro-oesophageal reflux disease. Lancet 367:2086-2100

5. Nandurkar S, Talley NJ (2000) Epidemiology and natural history of reflux disease. Best Pract Res Clin Gastroenterol 14:743-757

6. Smout AJ (2007) The patient with GORD and chronically recurrent problems. Best Pract Res Clin Gastroenterol 21:365-378
7. Stylopoulos N, Rattner DW (2005) The history of hiatal hernia surgery: from Bowditch to laparoscopy. Ann Surg 241:185-193

8. Jones MP, Sloan SS, Rabine JC et al (2001) Hiatal hernia size is the dominant determinant of esophagitis presence and severity in gastroesophageal reflux disease. Am J Gastroenterol 96:17111717

9. Mittal RK (1997) Hiatal hernia: myth or reality? Am J Med 103:33S-39S

10. Mittal RK (1993) Hiatal hernia and gastroesophageal reflux: another attempt to resolve the controversy. Gastroenterology 105:941-943

11. Moss SF, Kidd M, Modlin IM (2007) The status of the hiatus: the role of hernia in gastroesophageal reflux disease. J Clin Gastroenterol 41:S144-S153

12. Rydberg L, Ruth M, Lundell L (1999) Mechanism of action of antireflux procedures. Br J Surg 86:405-410

13. Allgood PC, Bachmann M (2000) Medical or surgical treatment for chronic gastrooesophageal reflux? A systematic review of published evidence of effectiveness. Eur J Surg 166:713-721

14. Cookson R, Flood C, Koo B et al (2005) Short-term cost effectiveness and long-term cost analysis comparing laparoscopic Nissen fundoplication with proton-pump inhibitor maintenance for gastro-oesophageal reflux disease. Br J Surg 92:700-706

15. Lundell L, Miettinen P, Myrvold HE et al (2007) Seven-year follow-up of a randomized clinical trial comparing proton-pump inhibition with surgical therapy for reflux oesophagitis. Br J Surg 94:198-203

16. Mahon D, Rhodes M, Decadt B et al (2005) Randomized clinical trial of laparoscopic Nissen fundoplication compared with proton-pump inhibitors for treatment of chronic gastro-oesophageal reflux. Br J Surg 92:695-699

17. Dallemagne B, Weerts J, Markiewicz S et al (2006) Clinical results of laparoscopic fundoplication at ten years after surgery. Surg Endosc 20:159-165

18. Coelho JC, Wiederkehr JC, Campos AC et al (1999) Conversions and complications of laparoscopic treatment of gastroesophageal reflux disease. J Am Coll Surg 189:356-361

19. Kamolz T, Granderath FA, Bammer T et al (2002) Dysphagia and quality of life after laparoscopic Nissen fundoplication in patients with and without prosthetic reinforcement of the hiatal crura. Surg Endosc 16:572-577 
20. Lundell L (2004) Complications after anti-reflux surgery. Best Pract Res Clin Gastroenterol 18:935-945

21. Wills VL, Hunt DR (2001) Dysphagia after antireflux surgery. $\mathrm{Br}$ J Surg 88:486-499

22. Bessell JR, Finch R, Gotley DC et al (2000) Chronic dysphagia following laparoscopic fundoplication. Br J Surg 87:1341-1345

23. Hayden J, Jamieson G (2006) Optimization of outcome after laparoscopic antireflux surgery. ANZ J Surg 76:258-263

24. Cadiere GB, Rajan A, Rqibate M et al (2006) Endoluminal fundoplication (ELF)—evolution of Esophy $\mathrm{X}^{\mathrm{TM}}$, a new surgical device for transoral surgery. Minim Invasive Ther Allied Technol 15:348-355

25. Aye RW, Hill LD, Kraemer SJ et al (1994) Early results with the laparoscopic Hill repair. Am J Surg 167:542-546

26. Hill LD, Kozarek RA, Kraemer SJ et al (1996) The gastroesophageal flap valve: in vitro and in vivo observations. Gastrointest Endosc 44:541-547

27. Kraemer SJ, Aye R, Kozarek RA et al (1994) Laparoscopic Hill repair. Gastrointest Endosc 40:155-159

28. Kraemer SJ, Kozarek RA, Carter BJ et al (2006) EsophyX endoluminal fundoplication for the treatment of severe chronic GERD: multiple tissue fasteners secure valvuloplasty as demonstrated in an animal model. Gastrointest Endosc 63:AB235

29. Cadiere GB, Rajan A, Germay O et al (2008) Endoluminal fundoplication by a transoral device for the treatment of GERD: a feasibility study. Surg Endosc 22:333-342

30. Hirano I, Richter JE (2007) ACG practice guidelines: esophageal reflux testing. Am J Gastroenterol 102:668-685

31. Lundell LR, Dent J, Bennett JR et al (1999) Endoscopic assessment of oesophagitis: clinical and functional correlates and further validation of the Los Angeles classification. Gut 45:172-180

32. Velanovich V (2007) The development of the GERD-HRQL symptom severity instrument. Dis Esophagus 20:130-134

33. Velanovich V, Vallance SR, Gusz JR et al (1996) Quality of life scale for gastroesophageal reflux disease. J Am Coll Surg 183:217-224

34. Pleskow D, Rothstein R, Lo S et al (2005) Endoscopic fullthickness plication for the treatment of GERD: 12-month followup for the North American open-label trial. Gastrointest Endosc 61:643-649

35. Rothstein R, Filipi C, Caca K et al (2006) Endoscopic fullthickness plication for the treatment of gastroesophageal reflux disease: a randomized, sham-controlled trial. Gastroenterology 131:704-712

36. Tseng D, Rizvi AZ, Fennerty MB et al (2005) Forty-eight-hour $\mathrm{pH}$ monitoring increases sensitivity in detecting abnormal esophageal acid exposure. J Gastrointest Surg 9:1043-1051

37. Tutuian R, Castell DO (2006) Diagnostic procedures in GERD: principles and values of esophageal manometry and $\mathrm{pH}$-monitoring. In: Granderath FA, Kamolz T, Pointner R (eds) Gastroesophageal reflux disease: principles of disease, diagnosis, and treatment. Springer, New York, pp 121-138

38. Portale G, Peters J, Hsieh CC et al (2007) When are reflux episodes symptomatic? Dis Esophagus 20:47-52

39. Pandolfino JE, Richter JE, Ours T et al (2003) Ambulatory esophageal $\mathrm{pH}$ monitoring using a wireless system. Am J Gastroenterol 98:740-749

40. Jobe BA, Kahrilas PJ, Vernon AH et al (2004) Endoscopic appraisal of the gastroesophageal valve after antireflux surgery. Am J Gastroenterol 99:233-243
41. Seltman AK, Kahrilas PJ, Chang EY et al (2006) Endoscopic measurement of cardia circumference as an indicator of GERD. Gastrointest Endosc 63:22-31

42. Gideon RM (2005) Manometry: technical issues. Gastrointest Endosc Clin N Am 15:243-255

43. Nayar DS, Khandwala F, Achkar E et al (2005) Esophageal manometry: assessment of interpreter consistency. Clin Gastroenterol Hepatol 3:218-224

44. Huber-Lang M, Henne-Bruns D, Schmitz B et al (2006) Esophageal perforation: principles of diagnosis and surgical management. Surg Today 36:332-340

45. Raghunath AS, O'Morain C, McLoughlin RC (2005) Review article: the long-term use of proton-pump inhibitors. Aliment Pharmacol Ther 22(Suppl 1):55-63

46. Jalving $M$, Koornstra JJ, Wesseling $J$ et al (2006) Increased risk of fundic gland polyps during long-term proton pump inhibitor therapy. Aliment Pharmacol Ther 24:1341-1348

47. Garcia Rodriguez LA, Ruigomez A, Panes J 2007) Use of acidsuppressing drugs and the risk of bacterial gastroenteritis. Clin Gastroenterol Hepatol 5:1418-1423

48. Fass R (2007) Erosive esophagitis and nonerosive reflux disease (NERD): comparison of epidemiologic, physiologic, and therapeutic characteristics. J Clin Gastroenterol 41:131-137

49. Johnson DA, Benjamin SB, Vakil NB et al (2001) Esomeprazole once daily for 6 months is effective therapy for maintaining healed erosive esophagitis and for controlling gastroesophageal reflux disease symptoms: a randomized, double-blind, placebocontrolled study of efficacy and safety. Am J Gastroenterol 96:27-34

50. Marchese M, Spada C, Costamagna G (2006) Endoluminal fundoplication. Minim Invasive Ther Allied Technol 15:356-365

51. Daniel MA (2007) EndoGastric solutions esophyX system with serosaFuse fasteners and accessories. U.S. Food and Drug Administration 510(k) Submission K071651:1-456

52. Wynyard M, Kletschka HD (1966) The crural branches of the phrenic nerves: their surgical significance. Minn Med 49:18211824

53. Fumagalli U, Bona S, Battafarano F et al (2007) Persistent dysphagia after laparoscopic fundoplication for gastro-esophageal reflux disease. Dis Esophagus. doi: 10.1111/j.1442-2050. 2007.00773.x

54. Soper NJ (1999) Laparoscopic management of hiatal hernia and gastroesophageal reflux. Curr Probl Surg 36:765-838

55. Bremner CG, Schlegel JF, Ellis FH Jr (1970) Studies of the "gastroesophageal sphincter mechanism": the role of the phrenoesophageal membrane. Surgery 67:735-740

56. Bombeck CT, Dillard DH, Nyhus LM (1966) Muscular anatomy of the gastroesophageal junction and role of phrenoesophageal ligament; autopsy study of sphincter mechanism. Ann Surg 164:643-654

57. Ciovica R, Gadenstatter M, Klingler A et al (2006) Quality of life in GERD patients: medical treatment versus antireflux surgery. $\mathrm{J}$ Gastrointest Surg 10:934-939

58. Kahrilas PJ (2001) Management of GERD: medical versus surgical. Semin Gastrointest Dis 12:3-15

59. Lundell L (2007) Therapy of gastroesophageal reflux: evidencebased approach to antireflux surgery. Dig Dis 25:188-196 